\title{
Cátedra de Estudios Afrocolombianos, escenario académico para propiciar la educación inclusiva e intercultural en Colombia
}

\begin{abstract}
Chair of Afro-Colombian Studies, Academic Setting to Promote Inclusive and Intercultural Education in Colombia
\end{abstract}

\section{Cadeira de Estudos Afro-Colombianos, ambiente acadêmico para promover a educação inclusiva e intercultural na Colômbia}

\author{
Andrés Felipe Velásquez Mosquera \\ Universidad del Tolima, Colombia \\ afvelasquezm@ut.edu.co \\ https://orcid.org/0000-0003-0492-668X
}

\section{Resumen}

El objetivo principal de esta investigación fue identificar los principales problemas que han frenado la implementación de la Cátedra de Estudios Afrocolombianos en Colombia desde su promulgación (1998). Para lograr este propósito, se utilizó una metodología con enfoque mixto, mediante un análisis documental de leyes, decretos, resoluciones y sentencias de la rama judicial, así como convenios internacionales firmados por Colombia con incidencia en dicha cátedra. Los principales resultados del análisis documental muestran que, en efecto, en la legislación colombiana existen diversas normas que soportan dicha cátedra, entre las que destaca el Decreto 804 de 1995 (Presidencia de la República de Colombia, 18 de mayo de 1995). Aunado a ello, se aplicó una encuesta a 68 líderes de las comunidades mencionadas que residen en diversas regiones de Colombia. Entre los resultados de la encuesta destaca que $56 \%$ de los líderes étnicos encuestados manifestó que la Cátedra de Estudios Afrocolombianos no se ha implementado en los currículos educativos por falta de políticas pertinentes y $19 \%$ atribuye dicha situación al desconocimiento por parte del Ministerio de 


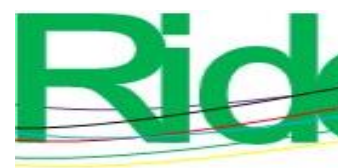

Revista Iberoamericana para la Investigación y el Desarrollo Educativo ISSN $2007-7467$

Educación Nacional y de las secretarías de educación sobre la realidad educativa que viven a diario al interior de los centros educativos los estudiantes pertenecientes a aquellas comunidades. Finalmente, se enfatiza en que la educación en Colombia continúa siendo excluyente por cuestiones raciales y que es poco abierta a la inclusión, a la diversidad étnica y cultural.

Palabras clave: Cátedra de Estudios Afrocolombianos, diversidad, inclusión, minorías étnicas.

\section{Abstract}

The main objective of this research was to identify the main problems that have slowed down the implementation of the Chair of Afro-Colombian Studies in Colombia since its promulgation (1998). To achieve this purpose, a methodology with a mixed approach was used, through a documentary analysis of laws, decrees, resolutions, and judgments of the judicial branch, as well as international agreements signed by Colombia with incidence in said chair. The main results of the documentary analysis show that, in effect, in Colombian legislation there are various norms that support said chair, among which Decree 804 of 1995 stands out (Presidencia de la República de Colombia, May 18, 1995). In addition to this, a survey was applied to 68 leaders of the aforementioned communities who reside in various regions of Colombia. Among the results of the survey, it stands out that $56 \%$ of the ethnic leaders surveyed stated that the Chair of Afro-Colombian Studies has not been implemented in the educational curricula due to a lack of relevant policies and 19\% attribute this situation to ignorance on the part of the Ministry of National Education and of the education secretariats on the educational reality that students belonging to those communities experience daily within the educational centers. Finally, it is emphasized that education in Colombia continues to be exclusive due to racial issues and that it is not very open to inclusion, ethnic and cultural diversity.

Keywords: Chair of Afro-Colombian Studies, diversity, inclusion, ethnical minorities. 


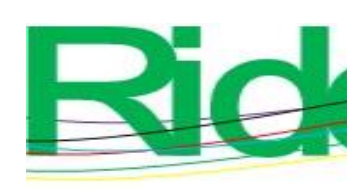

Revista Iberoamericana para la
Investigación y el Desarrollo Educativo
ISSN $2007-7467$

\section{Resumo}

O objetivo principal desta pesquisa foi identificar os principais problemas que têm impedido a implementação da Cátedra de Estudos Afro-Colombianos na Colômbia desde sua promulgação (1998). Para tanto, utilizou-se uma metodologia de abordagem mista, por meio de uma análise documental de leis, decretos, resoluções e sentenças do Poder Judiciário, bem como de acordos internacionais assinados pela Colômbia com incidência na referida cadeira. Os principais resultados da análise documental mostram que, com efeito, na legislação colombiana existem várias normas que apoiam a referida cadeira, entre as quais se destaca o Decreto 804 de 1995 (Presidência da República da Colômbia, 18 de maio de 1995). Além disso, foi aplicada uma pesquisa a 68 lideranças das comunidades mencionadas, residentes em diversas regiões da Colômbia. Entre os resultados da pesquisa, destaca-se que $56 \%$ dos líderes étnicos pesquisados afirmaram que a Cátedra de Estudos Afro-Colombianos não foi implementada nos currículos educacionais por falta de políticas relevantes e 19\% atribuem esta situação ao desconhecimento por parte do Ministério da Educação Nacional e das secretarias de educação sobre a realidade educacional que os alunos dessas comunidades vivenciam no cotidiano dos centros educacionais. Finalmente, destaca-se que a educação na Colômbia continua sendo exclusiva por questões raciais e que não está muito aberta à inclusão, à diversidade étnica e cultural.

Palavras-chave: Cátedra de Estudos Afro-Colombianos, diversidade, inclusão, minorias étnicas.

Fecha Recepción: Febrero 2021

Fecha Aceptación: Agosto 2021

\section{Introducción}

La Cátedra de Estudios Afrocolombianos se constituye como una oportunidad valiosa para propiciar el respeto por los derechos humanos, promover la diversidad étnica y cultural, la convivencia social y, en general, favorecer procesos de inclusión en la escuela. Los orígenes de esta cátedra, creada mediante el Decreto 1122 de 1998 (Presidencia de la República de Colombia, 23 de junio de 1998 ), subyacen en la Constitución política de 1991, la Ley 70 de 1993 (Congreso de Colombia, 31 de agosto de 1993), la Ley General de Educación de 1994 (Congreso de Colombia, 8 de febrero de 1994) y, específicamente, el Decreto 804 de 1995 (Presidencia de la República de Colombia, 18 de mayo de 1995). Pese a la trascendencia de aquella para las comunidades negra, afrocolombiana, raizal y 


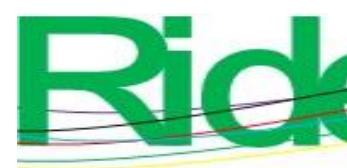

Revista Iberoamericana para la
Investigación y el Desarrollo Educativo ISSN $2007-7467$

palenquera, las expectativas, los anhelos y sueños por ver su implementación en el currículo y por observar su repercusión en la mejora de los derechos humanos de estos grupos étnicos se han ido diluyendo con el transcurrir del tiempo.

De hecho, han pasado más de 20 años desde la promulgación de esta cátedra y su implementación ha sido casi nula en la gran mayoría de las instituciones educativas, mientras que el Gobierno — representado por el Ministerio de Educación Nacional y las secretarías de educación - ha sido un convidado de piedra durante este período. Esta situación va de la mano con la ineficiencia de la Comisión Pedagógica de Comunidades Negras, creada mediante el Decreto 2249 de 1995 (Presidencia de la República de Colombia, 26 de diciembre de 1995), la cual debería impulsar el desarrollo y fortalecimiento de políticas educativas en pro de las comunidades afro del país.

Al hacer una indagación crítica de por qué esta cátedra no ha cumplido con su papel de propiciar procesos de inclusión, respeto por las diferencias étnicas y emancipación de las culturas de estos grupos raciales al interior de las instituciones educativas en el territorio nacional, se encuentra que el primer responsable es el Gobierno. La razón es que el Ministerio de Educación Nacional no ha mostrado voluntad política para la implementación de esta, tal como lo establece la ley, al ser consagrada como un hecho de carácter obligatorio en los currículos de los planteles educativos públicos y privados.

Actualmente, se observa un escalamiento de los problemas de racismo y exclusión al interior de las instituciones educativas a lo largo y ancho del territorio colombiano, ambiente que no es ajeno a lo vivido décadas atrás por las generaciones que antecedieron a las minorías étnicas asentadas en este país, las cuales fueron esclavizadas durante siglos. Por consiguiente, es trascendental implementar cuanto antes la Cátedra de Estudios Afrocolombianos para propiciar el respeto por la diferencia étnica, los derechos humanos, la inclusión, la equidad, contribuyendo a mejorar el clima escolar. Sobre todo, con ella se abren posibilidades para que los colombianos aprendan a reconocerse y a autorreconocerse como sujetos que conforman un país multiétnico y pluricultural, donde todos los grupos poblacionales han aportado a la construcción del Estado colombiano desde la diferencia étnica y cultural.

Esta situación expuesta, que va unida a la búsqueda bibliográfica, el ser miembro de la comunidad afrocolombiana y la experiencia docente de más de 10 años en varios grados y niveles de escolaridad, incluyendo la educación superior, llevó a plantear el siguiente problema de investigación: ¿cuáles son las principales dificultades que enfrenta la implementación de la Cátedra de Estudios Afrocolombianos en Colombia? 


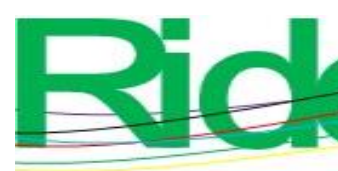

Revista Iberoamericana para la Investigación y el Desarrollo Educativo ISSN $2007-7467$

descriptivos e inductivos. Además, se asume una realidad desde la dinámica propia de los actores que participan en la investigación, así como a partir de datos reales, ricos en información y profundos para la interpretación de la situación abordada. Debe añadirse que es holística, no es generalizable y facilita el estudio de comunidades o pequeños grupos como instituciones educativas, situaciones en el aula de clases, etc.

Ahora bien, la investigación asumida es de enfoque descriptivo. De acuerdo con Hernández et al. (2014), con los estudios descriptivos se busca especificar las propiedades, las características y los perfiles de personas, grupos, comunidades, procesos, objetos o cualquier otro fenómeno que se someta a un análisis. Así, únicamente se permite medir o recoger información de manera independiente o conjunta sobre los conceptos o las variables a las que se refieren, de modo que su objetivo no es indicar cómo se relacionan estas.

En el mismo sentido, Cerda (1994) afirma que en la práctica investigativa se ha ido descubriendo que la mayoría de las contradicciones que se dan entre ambos paradigmas en conflicto no son tales, pues sus diferencias son secundarias y tienen un origen más teórico que práctico u operativo. En el trabajo de campo, los investigadores tienden a la articulación y complementación de diversos métodos, instrumentos y técnicas que utilizan en la labor investigativa, independientemente de que pertenezcan o se asocien con uno u otro paradigma. De esta forma, en la práctica se rompe con la idea de que la adopción de un paradigma implica la utilización de determinada metodología.

En coherencia con los planteamientos expuestos, de los métodos cuantitativos se acogieron las pruebas estadísticas de validez y confiabilidad de los instrumentos. En cuanto al aspecto cualitativo, se usó el análisis documental y un enfoque descriptivo, considerando las características de la población objeto de estudio y sus particularidades, para llegar a comprender su actividad en circunstancias importantes (Stake, 1998).

Como ya se indicó, la selección de las personas se hizo posterior a una fase diagnóstica, donde estuvieron involucrados los 230 líderes que integran el Espacio Nacional de Consulta Previa para Comunidades Negras, Afrocolombianas, Raizales y Palenqueras de todo el país. Posteriormente, se aplicó una muestra piloto que llevó a la selección definitiva de la muestra. Rodríguez, Gil y García (1996) destacan que el objeto de la investigación nace del contexto educativo, en el que el tiempo, el lugar y los participantes desempeñan un papel fundamental y en el que la observación directa es el medio imprescindible para recoger la información, realizada desde el punto de vista holístico. La triangulación constituye el proceso básico para la validación de los datos. 


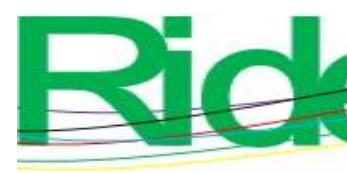

Revista Iberoamericana para la
Investigación y el Desarrollo Educativo
ISSN $2007-7467$

Asimismo, la interculturalidad es entendida como la capacidad de conocer la cultura propia y otras culturas que interactúan y se enriquecen de forma dinámica y recíproca; contribuye a plasmar en la realidad social el respeto por los derechos humanos, una coexistencia en igualdad de condiciones y respeto mutuo. La flexibilidad es la construcción permanente de los procesos etnoeducativos acordes con los valores culturales, las necesidades y particularidades de los grupos étnicos. Por su parte, la progresividad es entendida como la dinámica de los procesos etnoeducativos generada por la investigación que, articulados coherentemente, se consolidan y contribuyen al desarrollo del conocimiento. Finalmente, la solidaridad refiere a la cohesión del grupo alrededor de vivencias que le permiten fortalecerse y mantener su existencia en relación con los demás grupos sociales.

Para este estudio se realizó un análisis documental y un muestreo aleatorio simple estratificado y conformado por un grupo de 68 líderes pertenecientes a los 230 miembros que integran el Espacio Nacional de Consulta Previa para Comunidades Negras, Afrocolombianas, Raizales y Palenqueras. Este espacio alberga en su seno a la Comisión IV, encargada de asuntos educativos como el análisis de los problemas que hoy enfrenta la implementación de la Cátedra de Estudios Afrocolombianos. De ahí la pertinencia de haber seleccionado la muestra de este segmento de la población.

Por ello, se aplicó un test organizado mediante un cuestionario autodiligenciado, respondido voluntariamente por las personas con previo consentimiento informado. Para determinar el tamaño de la muestra, se utilizó la ecuación correspondiente al tamaño de la muestra para población finita (230 líderes) del Espacio Nacional de Consulta Previa para Comunidades Negras, Afrocolombianas, Raizales y Palenqueras.

$$
n=\frac{N * Z_{\propto}^{2} * p * q}{e^{2} *(N-1)+Z_{\propto}^{2}(* p * q)}
$$

$N=$ Tamaño de la población (230 líderes).

$n=$ Tamaño de la muestra.

$Z=$ Nivel de confianza (1.96 correspondiente a un nivel de confianza de $95 \%)$.

$p=$ Probabilidad de éxito (0.5).

$q=$ Probabilidad de fracaso $(0.5)$.

$e=$ Margen de error (0.1).

Con la ecuación usada anteriormente para determinar el tamaño de la muestra para población conocida, se obtuvo una muestra de 68 personas, con edades entre los 24 y los 57 , con un promedio de 38 años. Debe decirse que $57 \%$ son hombres y el restante, $43 \%$, 


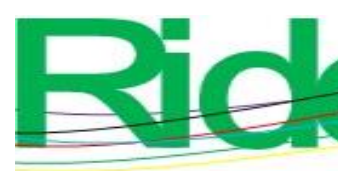

Revista Iberoamericana para la
Investigación y el Desarrollo Educativo
ISSN $2007-7467$

mujeres. Fue aplicado como instrumento un cuestionario de cinco preguntas, con el propósito de conocer la percepción acerca de los problemas con la implementación de la Cátedra de Estudios Afrocolombianos y otros aspectos relacionados con derechos humanos, exclusión y discriminación en la escuela de la República de Colombia.

La información recolectada fue ingresada y analizada mediante el programa IBM SPSS Statistics en su versión 26; el respectivo análisis descriptivo se efectuó de acuerdo con cada una de las preguntas planteadas en el cuestionario. Además, para el tratamiento de los datos, se cumplió con el derecho a la privacidad y conservación de la integridad personal de los participantes.

En lo relacionado con el instrumento de medición, se estima que este es confiable cuando él mismo mide lo que se quiere medir y es aplicado varias veces, con lo cual se obtiene un resultado similar.

Hernández et al. (2014) indican que "la confiabilidad de un instrumento de medición se refiere al grado en que su aplicación repetida al mismo sujeto u objeto produce iguales resultados" (p. 200).

Para la ejecución del procedimiento metodológico se aplicó la prueba piloto ya validada a personas que no formaban parte de la muestra, pero que presentaban las mismas características de los sujetos muestrales. Para hallar el coeficiente de confiabilidad, se procedió a la aplicación de una prueba piloto a un grupo de 10 sujetos con características equivalentes a la muestra de estudio. Además, se codificaron las respuestas, se hizo la trascripción de las respuestas en una matriz de tabulación de doble entrada con el apoyo del programa IBM SPSS Statistics versión 26 y, posteriormente, se efectuó el cálculo del coeficiente de alfa de Cronbach, y se obtuvo como resultado el valor de 0.8017 , que está en el intervalo $0.81-1.00$, considerado muy alto tomando como referencia la escala sugerida por Ruiz (1998). 


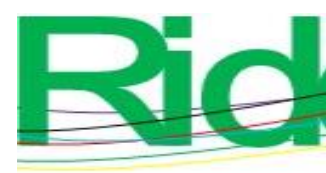

Revista Iberoamericana para la Investigación y el Desarrollo Educativo ISSN $2007-7467$

Tabla 1. Escala del coeficiente de alfa de Cronbach sugerida por Ruiz (1998)

\begin{tabular}{|l|l|}
\hline Rango & Magnitud \\
\hline $0.81-1.00$ & Muy alta \\
\hline $0.61-0.80$ & Alta \\
\hline $0.41-0.60$ & Moderada \\
\hline $0.21-0.40$ & Baja \\
\hline $0.001-0.20$ & Muy baja \\
\hline
\end{tabular}

Fuente: Elaboración propia con base en Ruiz (1998)

De esta forma, se constató que el instrumento diseñado posee una buena consistencia interna y, en consecuencia, era válido y confiable para ser aplicado a la población de estudio.

Para realizar el análisis documental, se procedió a efectuar una búsqueda bibliográfica relacionada con la Cátedra de Estudios Afrocolombianos. Para ello, se recurrió a convenios internacionales suscritos por Colombia, a leyes, decretos y resoluciones emanadas del Gobierno nacional, sentencias de la Corte Constitucional de Colombia en favor de los grupos étnicos pertenecientes a comunidades negras, afrocolombianas, raizales y palenqueras, así como a trabajos de grado y artículos relativos al tema en cuestión.

A continuación, se presentan los resultados obtenidos con el análisis documental.

\section{Resultados}

Se realizó un análisis documental con el propósito de identificar las principales dificultades que ha enfrentado la implementación de la Cátedra de Estudios Afrocolombianos en instituciones educativas colombianas desde su creación (hace más de 20 años) hasta la actualidad. Además, se valoraron las implicaciones de esta en cuanto a la defensa de los derechos humanos, la diversidad cultural y la inclusión para las comunidades negra, afrocolombiana, raizal y palenquera.

Por ello, se incluyeron varios documentos que a continuación se enuncian: la Constitución Política de Colombia de 1991, la Ley General de Educación de 1994 (Congreso de Colombia, 8 de febrero de 1994), el Decreto 804 de 1995 (Presidencia de la República de Colombia, 18 de mayo de 1995), el Decreto 1627 en 1996 (Presidencia de la República de Colombia, 13 de septiembre de 1996), la Ley 70 de 1993 (Congreso de Colombia, 31 de agosto de 1993), el Decreto 1122 de 1998 (Presidencia de la República de Colombia, 23 de junio de 1998), los lineamientos curriculares Cátedra de Estudios Afrocolombianos, el 


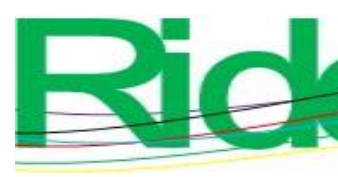

Revista Iberoamericana para la Investigación y el Desarrollo Educativo ISSN $2007-7467$

Decreto 2249 de 1995 (Presidencia de la República de Colombia, 26 de diciembre de 1995), el Convenio 169 de la Organización Internacional del Trabajo [OIT] (2014), la Resolución 57/249 de la Asamblea General de la Organización de las Naciones Unidas [ONU] (2001) y la Sentencia T-496/96 (Corte Constitucional, 26 de septiembre de 1996).

Los artículos 7, 8, 13, 67 y 68 de la Constitución política de 1991 de Colombia reconocen la diversidad étnica y cultural. Concretamente, el artículo 7 expresa lo siguiente: "El Estado reconoce y protege la diversidad étnica y cultural de la Nación colombiana". El artículo 8 señala que "es obligación del Estado y de las personas proteger las riquezas culturales y naturales de la Nación”. Por su parte, el artículo 13 indica:

Todas las personas nacen libres e iguales ante la ley, recibirán la misma protección y trato de las autoridades y gozarán de los mismos derechos, libertades y oportunidades sin ninguna discriminación por razones de sexo, raza, origen nacional o familiar, lengua, religión, opinión política o filosófica.

El artículo 67 establece que "la educación formará al colombiano en el respeto a los derechos humanos, a la paz y a la democracia; y en la práctica del trabajo y la recreación, para el mejoramiento cultural, científico, tecnológico y para la protección del ambiente”. Y el artículo 68 precisa que "los integrantes de los grupos étnicos tendrán derecho a una formación que respete y desarrolle su identidad cultural".

Aunado a ello, producto de las luchas de las comunidades negras, afrocolombianas, raizales y palenqueras del país, se promulgó la Ley 70 de 1993 (Congreso de Colombia, 31 de agosto de 1993). Con esta se dio inicio a una serie de políticas de reconocimiento de derechos en favor de estos grupos étnicos, principalmente por la vía de decretos, sentencias judiciales y por medio de acuerdos entre el Gobierno y estos grupos. De hecho, se puede decir que con la Ley 70 de 1993 (Congreso de Colombia, 31 de agosto de 1993) se crearon los cimientos para una educación propia apoyada en la identidad cultural, los intereses de los grupos étnicos y la necesidad de la población.

En efecto, uno de los objetivos de la Ley 70 de 1993 (Congreso de Colombia, 31 de agosto de 1993), previsto en el artículo 1, fue que el Estado se comprometiera a velar por la protección de la cultura para este grupo étnico. Específicamente:

Establecer mecanismos para la protección de la identidad cultural y de los derechos de las comunidades negras de Colombia como grupo étnico, y el fomento de su desarrollo económico y social, con el fin de garantizar que estas comunidades obtengan condiciones reales de igualdad de oportunidades frente 


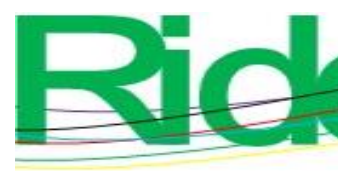

Revista Iberoamericana para la
Investigación y el Desarrollo Educativo
ISSN $2007-7467$

al resto de la sociedad colombiana (Congreso de Colombia, 31 de agosto de 1993)

Siguiendo con las normas favorables a las poblaciones negra, afrocolombiana, raizal y palenquera, el Decreto 804 de 1995 (Presidencia de la República de Colombia, 18 de mayo de 1995), construido sobre los pilares de la Ley 70 de 1993 (Congreso de Colombia, 31 de agosto de 1993), la Ley General de Educación de 1994 (Congreso de Colombia, 8 de febrero de 1994) y la Constitución Política de 1991, estableció los principios de la etnoeducación en Colombia al reglamentar la atención educativa para grupos étnicos. Así lo demuestra el artículo 2 de este decreto:

Artículo 2. Son principios de la etnoeducación:

a) Integralidad, entendida como la concepción global que cada pueblo posee y que posibilita una relación armónica y recíproca entre los hombres, su realidad social y la naturaleza;

b) Diversidad lingüística, entendida como las formas de ver, concebir y construir el mundo que tienen los grupos étnicos, expresadas a través de las lenguas que hacen parte de la realidad nacional en igualdad de condiciones;

c) Autonomía, entendida como el derecho de los grupos étnicos para desarrollar sus procesos etnoeducativos;

d) Participación comunitaria, entendida como la capacidad de los grupos étnicos para orientar, desarrollar y evaluar sus procesos etnoeducativos, ejerciendo su autonomía;

e) Interculturalidad, entendida como la capacidad de conocer la cultura propia y otras culturas que interactúan y se enriquecen de manera dinámica y recíproca, contribuyendo a plasmar en la realidad social una coexistencia en igualdad de condiciones y respeto mutuo;

f) Flexibilidad, entendida como la construcción permanente de los procesos etnoeducativos, acordes con los valores culturales, las necesidades y particularidades de los grupos étnicos;

g) Progresividad, entendida como la dinámica de los procesos etnoeducativos generada por la investigación que, articulados coherentemente, se consolidan y contribuyen al desarrollo del conocimiento, $\mathrm{y}$ 
h) Solidaridad, entendida como la cohesión del grupo alrededor de sus vivencias que le permite fortalecerse y mantener su existencia, en relación con los demás grupos sociales (Presidencia de la República de Colombia, 18 de mayo de 1995).

A continuación, se presenta una serie de tablas e imágenes y sus respectivos análisis sobre las preguntas que respondieron las personas seleccionadas del Espacio Nacional de Consulta Previa para Comunidades Negras, Afrocolombianas, Raizales y Palenqueras pertenecientes a varias regiones de Colombia. Se iniciará este proceso con la primera pregunta, “¿A qué razones atribuye que, transcurridos más de 20 años de la promulgación del Decreto 1122 de 1998 (Presidencia de la República de Colombia, 23 de junio de 1998) que creó la Cátedra de Estudios Afrocolombianos, esta aún no se haya implementado en la mayoría de las instituciones de educación básica y media del país?”. La información obtenida se presenta en la tabla 2 y en la figura 1 , seguidos del correspondiente análisis.

Tabla 2. Distribución de frecuencia y porcentaje de las respuestas de la pregunta uno

\begin{tabular}{|l|c|c|}
\hline \multicolumn{1}{|c|}{ Opciones de respuesta } & Frecuencia & Porcentaje \\
\hline Falta de políticas pertinentes para su implementación. & 23 & 33.82 \\
\hline $\begin{array}{l}\text { Falta de organización de los grupos étnicos para exigir su } \\
\text { implementación. }\end{array}$ & 15 & 22.06 \\
\hline $\begin{array}{l}\text { Desconocimiento de la realidad educativa y cultural por } \\
\text { parte del Ministerio Nacional de Educación. }\end{array}$ & 13 & 13.12 \\
\hline Por ser un grupo poblacional con desventaja social. & 8 & 11.76 \\
\hline No sabe/ No responde. & 68 & 100 \\
\hline Total & 9 & \\
\hline
\end{tabular}

Fuente: Elaboración propia

A continuación, se muestra la figura con los porcentajes correspondientes a las diferentes opciones sobre las razones por las cuales, transcurridos más de 20 años de la expedición de la ley que creó la Cátedra de Estudios Afrocolombianos, esta aún no ha sido implementada en la gran mayoría de instituciones educativas de Colombia. 


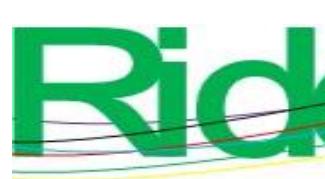

Revista Iberoamericana para la Investigación y el Desarrollo Educativo ISSN $2007-7467$

A continuación se realiza el análisis de la pregunta número dos de la encuesta.

Tabla 3. “Algún familiar, conocido o usted han sido discriminados en la escuela o universidad por su condición étnica?” Distribución de frecuencia y porcentaje con base en las respuestas de la pregunta dos

\begin{tabular}{|l|c|c|}
\hline \multicolumn{1}{|c|}{ Categoría } & Frecuencia & Porcentaje \\
\hline Casi siempre. & 17 & 25.00 \\
\hline Siempre. & 34 & 50.00 \\
\hline No sabe/No responde. & 4 & 5.88 \\
\hline Nunca. & 4 & 5.88 \\
\hline Casi nunca. & 9 & 13.24 \\
\hline Total & 68 & 100 \\
\hline
\end{tabular}

Fuente: Elaboración propia

En seguida se presenta la figura 2 con los porcentajes correspondientes a las diversas respuestas sobre casos de discriminación en la escuela por razones étnicas.

Figura 1. “¿Algún familiar, conocido o usted han sido discriminados en la escuela o universidad por su condición étnica?"

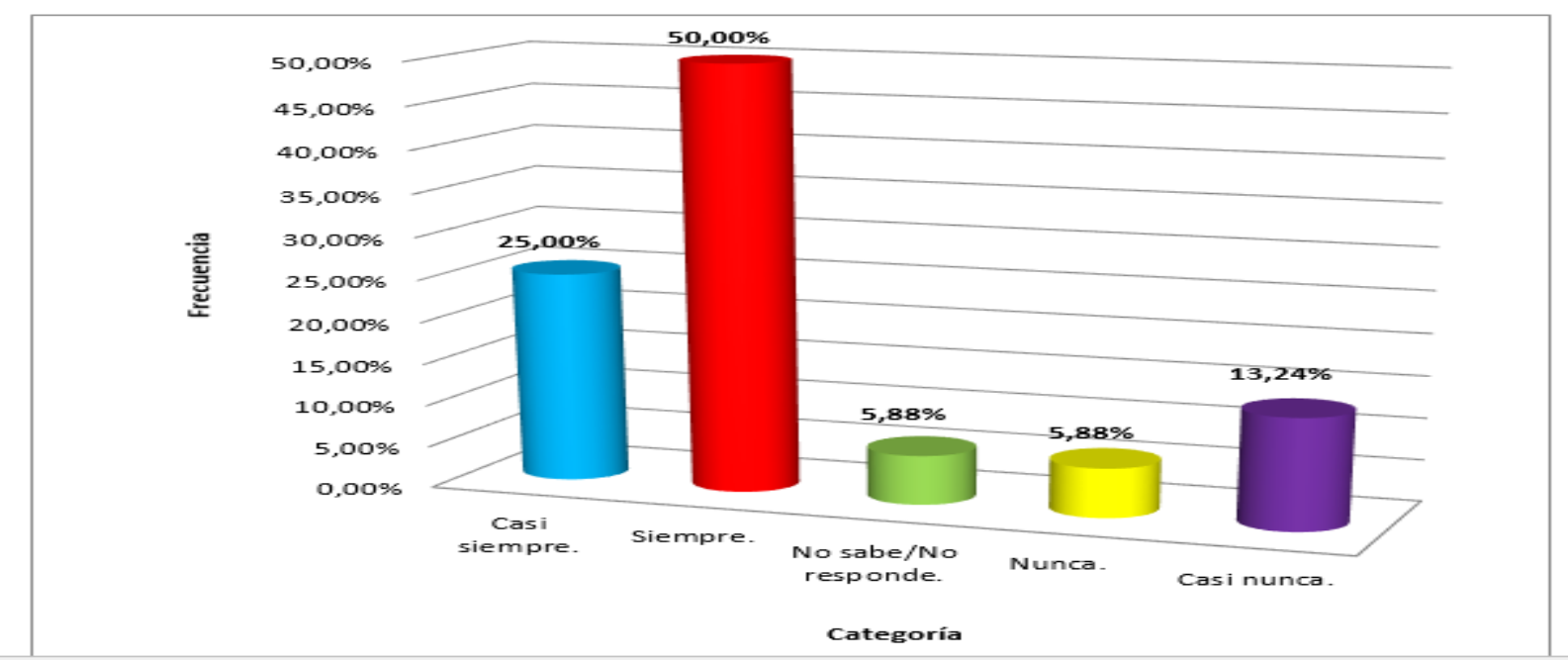

Fuente: Elaboración propia 


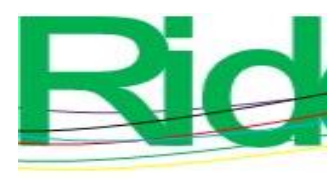

e

Revista Iberoamericana para la Investigación y el Desarrollo Educativo ISSN 2007 - 7467

Con respecto a la pregunta dos, $75 \%$ de los encuestados que pertenece a las comunidades negra, afrocolombiana, raizal y palenquera afirma que siempre o casi siempre ha sido víctima o ha escuchado algún tipo de discriminación de su grupo étnico en la escuela; $19.12 \%$ manifiesta que nunca o casi nunca ha sido víctima o ha escuchado de casos de discriminación en la escuela. Por su parte, solo $5.88 \%$ de los encuestados no sabe o no responde. Esta información se puede ver reflejada en la tabla y figura anterior, donde la mayoría de los encuestados dice haber sido o conocer de personas de su grupo étnico que se han sentido discriminadas en la escuela o en la universidad por su color de piel.

La tercera pregunta que se propuso fue "Para usted, ¿qué deberían hacer el Ministerio de Educación y las secretarías de educación para promover el respeto por los derechos humanos, la diversidad e inclusión en las escuelas y universidades de Colombia?”

Tabla 4. Distribución de frecuencia y porcentaje con base en las respuestas de la pregunta tres

\begin{tabular}{|l|c|c|}
\hline \multicolumn{1}{|c|}{ Categoría } & Frecuencia & Porcentaje \\
\hline $\begin{array}{l}\text { Desarrollar políticas públicas sobre derechos } \\
\text { humanos, etnoeducación, diversidad e } \\
\text { inclusión en la escuela. }\end{array}$ & 33 & 48.53 \\
\hline $\begin{array}{l}\text { Implementar la Cátedra de Estudios } \\
\text { Afrocolombianos. }\end{array}$ & 17 & 25.00 \\
\hline $\begin{array}{l}\text { Propiciar espacios de participación cultural } \\
\text { de los grupos étnicos al interior de la escuela. }\end{array}$ & 8 & 11.76 \\
\hline $\begin{array}{l}\text { Promover espacios de autorreconocimiento } \\
\text { étnico. }\end{array}$ & 7 & 10.29 \\
\hline No sabe/ No responde. & 68 & 4.41 \\
\hline Total & 3 & 100 \\
\hline
\end{tabular}

Fuente: Elaboración propia

A continuación se presenta la figura 3, que corresponde a la pregunta número tres. 

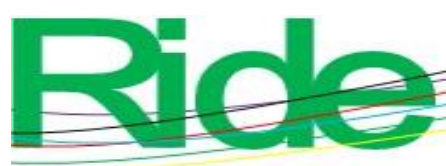

Revista Iberoamericana para la Investigación y el Desarrollo Educativo ISSN 2007 - 7467

Figura 2. "Para usted, ¿qué deberían hacer el Ministerio de Educación y las secretarías de educación para promover el respeto por los derechos humanos, la diversidad e inclusión en las escuelas y universidades de Colombia?"

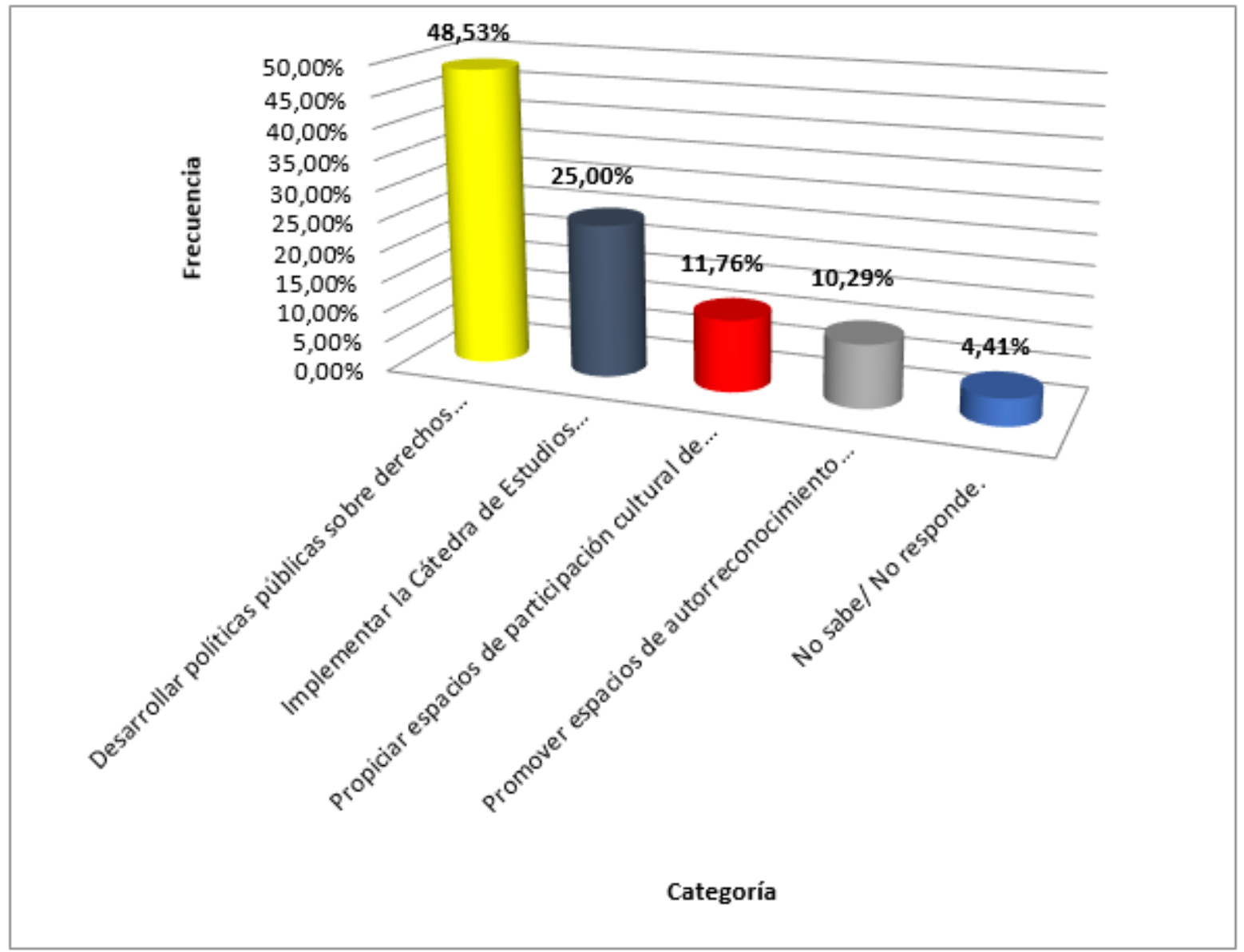

Fuente: Elaboración propia

La figura 3 muestra que $48.53 \%$ de los encuestados considera que el Ministerio de Educación Nacional y las secretarías de educación deben desarrollar políticas públicas sobre derechos humanos, etnoeducación, diversidad e inclusión en la escuela. Para $25 \%$, se debe implementar la Cátedra de Estudios Afrocolombianos. Por su parte, $22.06 \%$ piensa que se deben propiciar espacios de participación cultural de los grupos étnicos al interior de la escuela o promover espacios de autorreconocimiento étnico, mientras que tan solo un $4.41 \%$ no sabe o no responde nada.

La tabla 4 y figura 4 representan y consolidan las respuestas dadas por las personas encuestadas a partir de la pregunta “¿Cuáles son los principales efectos negativos que causan en los estudiantes de las minorías étnicas la discriminación y exclusión en la escuela y la universidad?" 
Tabla 5. Distribución de frecuencia y porcentaje con base en las respuestas de la pregunta cuatro

\begin{tabular}{|l|c|c|}
\hline \multicolumn{1}{|c|}{ Categoría } & Frecuencia & Porcentaje \\
\hline Desmotivación por asistir a la escuela. & 43 & 63.24 \\
\hline Baja autoestima. & 12 & 17.65 \\
\hline $\begin{array}{l}\text { Dificultad para socializar con otras } \\
\text { personas. }\end{array}$ & 8 & 11.76 \\
\hline $\begin{array}{l}\text { Alto grado de dependencia de sus } \\
\text { padres. }\end{array}$ & 4 & 5.88 \\
\hline No sabe/No responde. & 68 & 1.47 \\
\hline Total & & 100 \\
\hline
\end{tabular}

\section{Fuente: Elaboración propia}

Enseguida, se observa la figura con los porcentajes correspondientes a diversas respuestas emitidas por los encuestados sobre discriminación en escuelas y colegios colombianos.

Figura 3. “Cuáles son los principales efectos negativos que causan en los estudiantes de las minorías étnicas la discriminación y exclusión en la escuela y la universidad?"

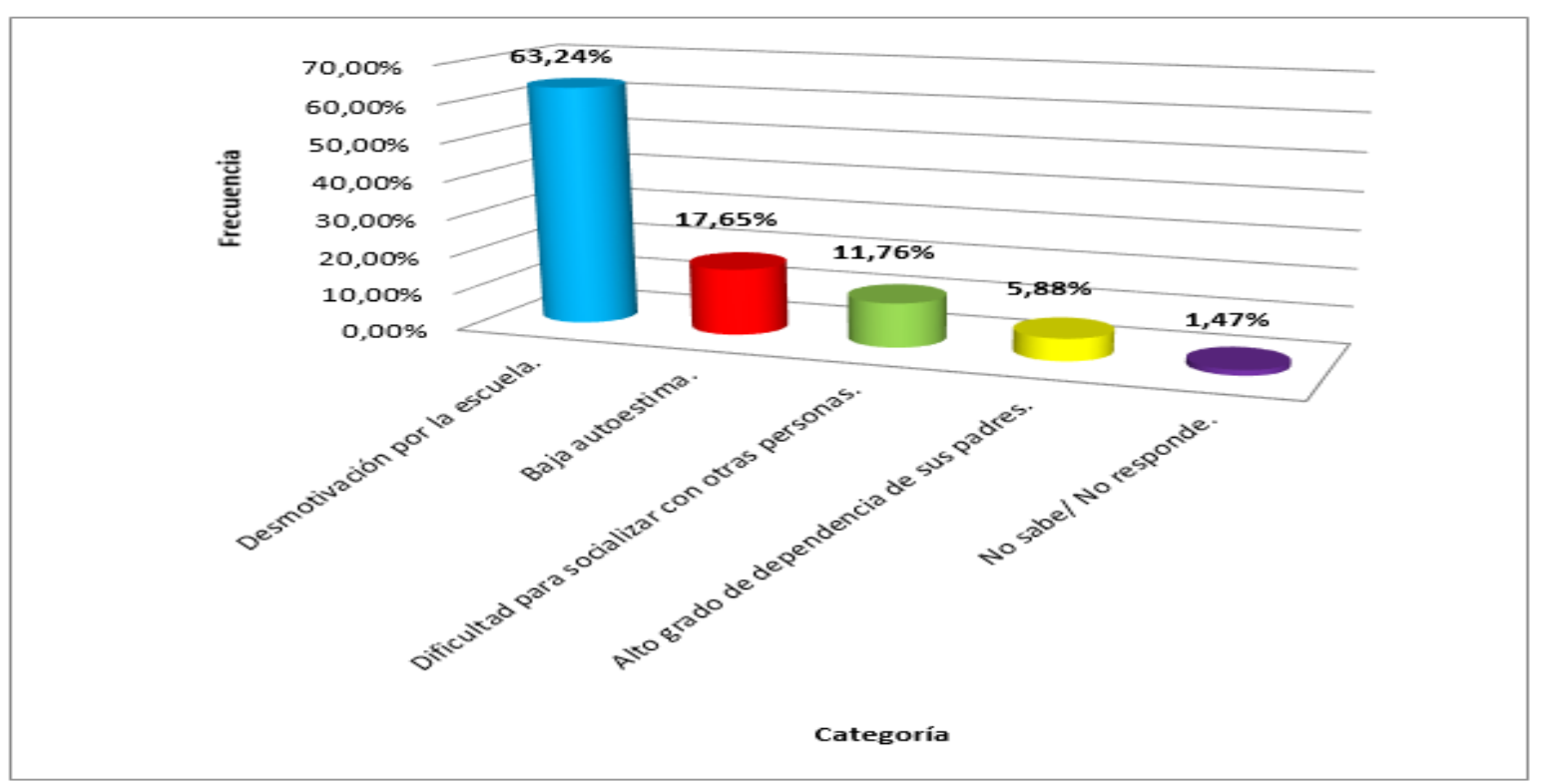

Fuente: Elaboración propia 


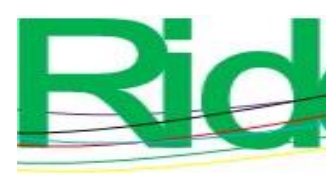

.

Revista Iberoamericana para la Investigación y el Desarrollo Educativo

ISSN 2007 - 7467

Como se puede observar en la figura anterior, el 63, 24\% de los encuestados afirma que la discriminación por razones étnicas en escuelas y universidades produce desmotivación en los estudiantes para ir a estudiar a estos centros educativos. El 17,65\% sostiene que lo mencionado produce baja autoestima. Un 11,76\% cree que dificulta la socialización de los estudiantes con otras personas. Un $5,88 \%$ piensa que aquella crea un alto grado de dependencia respecto de los padres, mientras que tan solo el $1,47 \%$ no sabe o no responde.

Por último, la pregunta cinco, “¿Por qué es importante implementar la Cátedra de Estudios Afrocolombianos en escuelas y universidades en la República de Colombia?”, generó las respuestas contenidas en la tabla 5.

Tabla 6. Distribución de frecuencia y porcentaje con base en las respuestas de la pregunta cinco

\begin{tabular}{|l|c|c|}
\hline Categoría & Frecuencia & Porcentaje \\
\hline $\begin{array}{l}\text { Promueve la integración cultural de } \\
\text { diversos actores de la comunidad dentro y } \\
\text { fuera de la escuela. }\end{array}$ & 15 & 22.06 \\
\hline $\begin{array}{l}\text { Propicia el respeto por los derechos } \\
\text { humanos. }\end{array}$ & 24 & 35.29 \\
\hline $\begin{array}{l}\text { Promueve la diversidad e inclusión en la } \\
\text { comunidad. }\end{array}$ & 19 & 27.94 \\
\hline $\begin{array}{l}\text { Desarrolla procesos de formación integral } \\
\text { entre estudiantes, profesores y } \\
\text { administrativos. }\end{array}$ & 8 & 11.76 \\
\hline No sabe/No responde. & 68 & 2.94 \\
\hline Total & & 100 \\
\hline
\end{tabular}

Fuente: Elaboración propia

La figura 5 presenta los porcentajes correspondientes a las diversas opciones de respuesta que emitieron los encuestados relacionadas con la relevancia de la Cátedra de Estudios Afrocolombianos. 

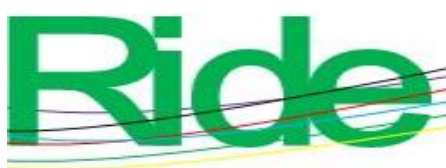

Revista Iberoamericana para la Investigación y el Desarrollo Educativo ISSN $2007-7467$

Figura 4. “¿Por qué es importante implementar la Cátedra de Estudios Afrocolombianos en escuelas y universidades en la República de Colombia?"

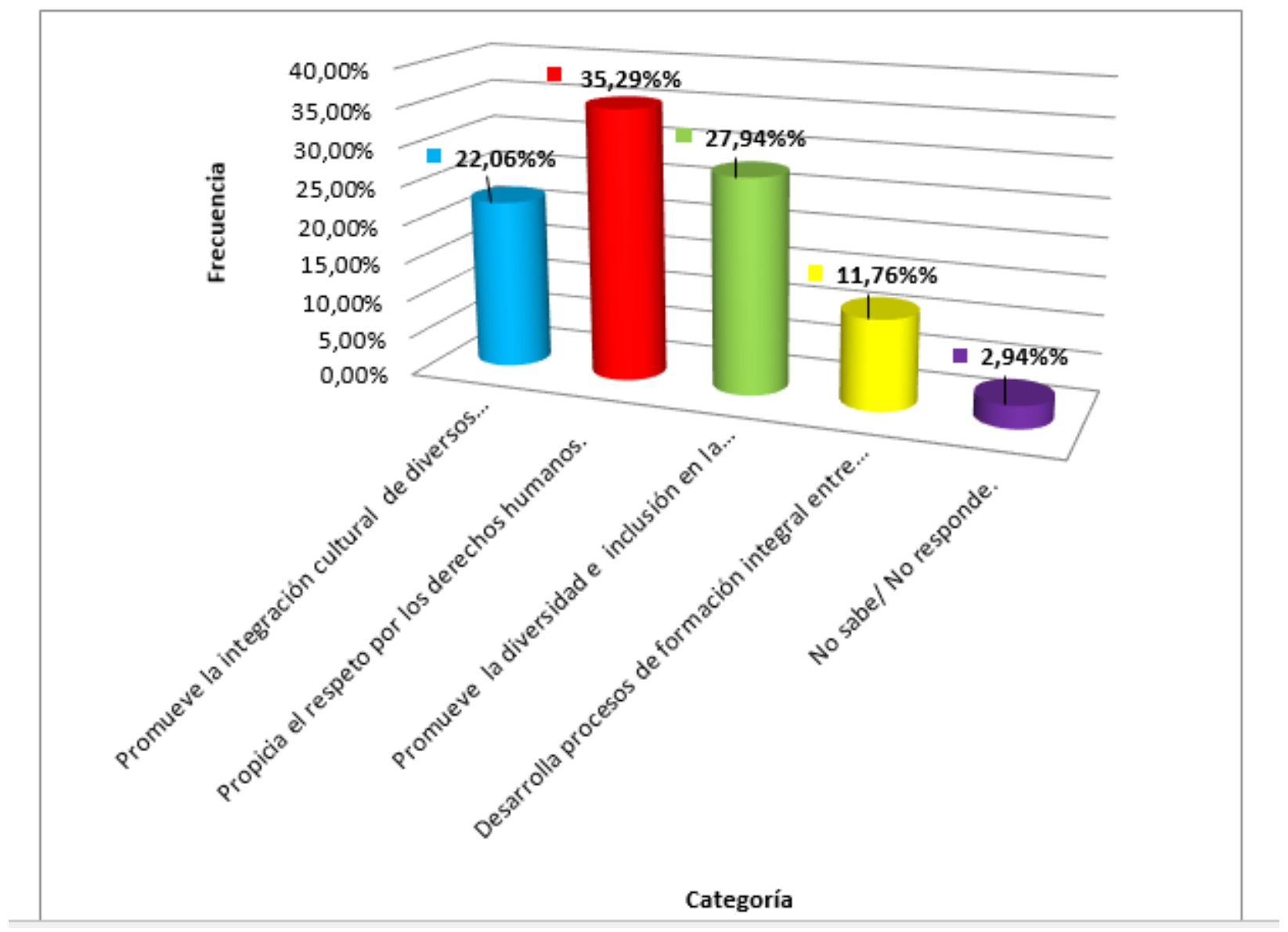

Fuente: Elaboración propia

La figura anterior muestra que $57.35 \%$ de los encuestados considera que la implementación de la Cátedra de Estudios Afrocolombianos es necesaria en las instituciones educativas de los diversos niveles de escolaridad en la República de Colombia porque promueve la integración cultural de diversos actores de la comunidad dentro y fuera de la escuela, o porque propicia el respeto por los derechos humanos. Por su parte, $27.94 \%$ opina que dicha cátedra promueve la diversidad e inclusión en la comunidad. Finalmente, mientras que $11.76 \%$ está de acuerdo en que la cátedra desarrolla procesos de formación integral entre estudiantes, profesores y administrativos, tan solo un $2.94 \%$ no sabe o no respondió. 


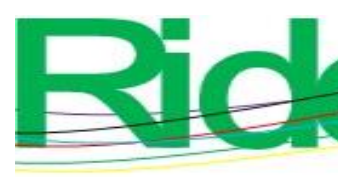

Revista Iberoamericana para la Investigación y el Desarrollo Educativo ISSN 2007-7467

\section{Discusión}

A propósito de los resultados obtenidos en la primera pregunta (tabla 2 y figura 1), Skliar (2002) afirma que la cuestión de cómo miramos al otro, desde dónde, con qué ideas y cómo lo excluimos cuando nos referimos a nosotras o nosotros con una frase muy significativa: hay "demasiada ausencia del otro en nosotros" (p. 14). Ello es importante porque las frases descalificativas que se usan a diario en la escuela desmotivan y afectan la personalidad de los estudiantes negros, afrocolombianos, raizales y palenqueros. Como se observa en las respuestas de la tabla 2 y en el análisis documental, se puede inferir que no ha habido voluntad política del Gobierno nacional por implementar la Cátedra de Estudios Afrocolombianos en el currículo de las instituciones educativas en los diversos niveles de escolaridad.

Según López (2001):

Una cultura de la diversidad no consiste en que las culturas minoritarias se vean sometidas a las condiciones que le imponga la cultura hegemónica, sino justamente lo contrario; la cultura de la diversidad exige que sea la sociedad la que cambie sus comportamientos y sus actitudes con respecto a los colectivos marginados (p. 45).

En cuanto a los resultados expuestos en la tabla 2 y en la figura 2, se debe señalar que el racismo en la escuela está siendo objeto de reflexión por parte de organizaciones que luchan por la defensa de derechos humanos en Colombia, incluidas organizaciones no gubernamentales (ONG), la Defensoría del Pueblo, la Personería y la ONU, entre otras organizaciones.

Con respecto a lo observado y analizado en la tabla 3 y la figura 3 , se puede inferir que existe preocupación en parte de la sociedad colombiana por la defensa de los derechos humanos. Por ello, se resalta la necesidad de poner en escena una política pública a este respecto, así como promover la diversidad e inclusión en la escuela por medio de espacios de reflexión entre esta y la sociedad.

Del mismo modo, las comunidades negra, afrocolombiana, raizal y palenquera esperan que el Ministerio de Educación Nacional ponga en ejecución políticas educativas que promuevan la etnoeducación, la interculturalidad e inclusión. Debe decirse que estos grupos étnicos se quejan por el incumplimiento de lo previsto en la Constitución Política de 1991, en la Ley 70 de 1993 (Congreso de Colombia, 31 de agosto de 1993) y en los decretos 


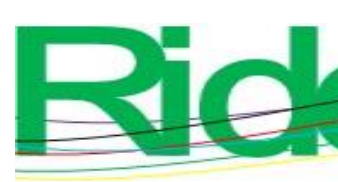

Revista Iberoamericana para la Investigación y el Desarrollo Educativo ISSN $2007-7467$

reglamentarios como el que creó la Cátedra de Estudios Afrocolombianos, normatividad que gira en torno al respeto por los derechos humanos, a la diversidad étnica y cultural.

Con base en lo expuesto en los resultados presentados en la tabla 4 y la figura 4 , se puede decir que esta exclusión escolar se encuentra ligada a la exclusión social (Freire, 1990). En ese orden de ideas, el factor político está relacionado con el lugar donde se vive y el ámbito de desarrollo del educando. Por tanto, se requieren políticas públicas por parte del Gobierno colombiano para contribuir a fortalecer la defensa de los derechos humanos y a erradicar la discriminación racial, promoviendo la diversidad e inclusión de los grupos étnicos al interior de las instituciones educativas y de la sociedad en general.

Para finalizar este apartado, con base en los resultados reflejados en la tabla 5 y la figura 5, es válido retomar las palabras de Freire (2001): "El sueño de un mundo mejor nace de las entrañas de su contrario" (p. 145). Esto implica asumir que solo si las personas son conscientes de los problemas que implica el racismo, la exclusión y el irrespeto por los derechos humanos, vivenciando esta situación desde su propia realidad, podrán luchar en contra de los mismos. En consecuencia, la escuela colombiana requiere la inclusión de la Cátedra de Estudios Afrocolombianos en el currículo, de tal manera que contribuya a promover el respeto por los derechos humanos, la diversidad étnica y cultural. Lo anterior implica educar para la formación en valores, la participación, la inclusión y la democracia.

En términos de Fricker (2007), la vulneración de los derechos de estos grupos étnicos pertenecientes a las comunidades negra, afrocolombiana, raizal y palenquera se puede explicar desde la injusticia epistémica. De hecho, está claro que hay un desconocimiento por parte del Ministerio de Educación Nacional del contexto histórico-social en el que han vivido por siglos estas poblaciones, lo que implica tener en cuenta la esclavización, la marginalidad e invisibilización en que han vivido. En efecto, sus discursos sociales, sus quejas, sus reclamos verbales y sus prácticas culturales, entre otras situaciones, han sido apagadas bajo el término de minoría étnica, remarcando la idea de un grupo con desventaja social, sin poder político ni económico, situación que afecta los derechos humanos y la dignidad de esta población.

La investigación realizada por el Ministerio del Interior de la República de Colombia denominada (2019) "Diagnóstico: implementación de la Cátedra de Estudios Afrocolombianos, experiencias y perspectivas en el respecto de la diversidad étnica, y cultural de la nación”, confirma los resultados que hemos mostrado a lo largo de esta investigación. En el capítulo 5 el estudio del Ministerio del Interior devela que el 55,2\% 


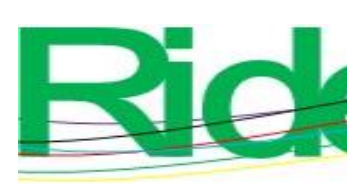

Revista Iberoamericana para la
Investigación y el Desarrollo Educativo
ISSN $2007-7467$

Las escuelas normales superiores y las instituciones de educación superior, que posean una Facultad de Educación, tendrán en cuenta experiencias, contenidos y prácticas pedagógicas relacionados con los estudios afrocolombianos, en el momento de elaborar los correspondientes currículos y planes de estudio, atendiendo a los requisitos de creación y funcionamiento de sus respectivos programas académicos de formación de docentes.

Así pues, el análisis documental realizado arroja que es preocupante la situación de racismo y exclusión que viven cotidianamente los escolares. Esto sucede de forma particular con comunidades negras, afrocolombianas, raizales y palenqueras, pues constantemente son objeto de burlas por su forma de vestir, hablar y, en general, por sus manifestaciones culturales. Esta situación es contraria a lo previsto en la normatividad colombiana, particularmente en lo contemplado por el Decreto 1122 de 1988 (Presidencia de la República de Colombia, 23 de junio de 1998), que creó la Cátedra de Estudios Afrocolombianos, la Ley General de Educación (Congreso de Colombia, 8 de febrero de 1994) y lo expresado en los artículos 7 y 8 de la Constitución Política de Colombia.

El mismo análisis permitió observar que la gran mayoría de las organizaciones educativas públicas y privadas del país siguen sin incluir en sus currículos los lineamientos de la Cátedra de Estudios Afrocolombianos en sus proyectos educativos institucionales. Desde la experiencia, se puede considerar que su inclusión contribuiría a propiciar el respeto por la diversidad cultural y los derechos humanos. De acuerdo con Somin (2010), la ignorancia política socava las explicaciones normativas de la legitimidad democrática, pues las normas constituyen un ideal, mas no un intento por explicar la realidad existente. Sin embargo, un ideal normativo debería ser posible, por lo que la ignorancia política genera serias dudas sobre la viabilidad de la democracia deliberativa.

Pese a las múltiples dificultades y a los tropiezos en la implementación de la Cátedra de Estudios Afrocolombianas, hay que resaltar que en el país en la mayoría de planteles educativos se cuenta con un grupo de docentes negros, afrocolombianos, raizales y palenqueros. Ellos han iniciado por cuenta propia un proceso de cualificación en temas de etnoeducación y afrocolombianidad, lo cual ha contribuido al desarrollo del autorreconocimiento. Esto mismo ha permitido el fortalecimiento de su cultura y el respeto por los derechos humanos en territorios con predominio de estos grupos étnicos.

El tema de la etnoeducación y la preservación de la diversidad cultural se encuentran enmarcados en diversos documentos oficiales, entre ellos la Constitución Política de 1991 (Const., 1991), la Ley 70 de 1993 (Congreso de Colombia, 31 de agosto de 1993), 


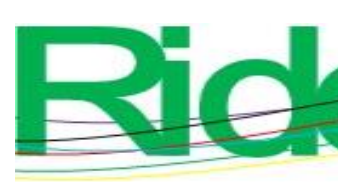

Revista Iberoamericana para la Investigación y el Desarrollo Educativo ISSN $2007-7467$

la 115 de 1994 (Congreso de Colombia, 8 de febrero de 1994), el Decreto 804 de 1995 (Presidencia de la República de Colombia, 18 de mayo de 1995) y el Decreto 1122 de 1998 (Presidencia de la República de Colombia, 23 de junio de 1998). En estas normas se reconoce que el Estado colombiano es un país multiétnico y pluricultural. Ello se puede ver en los artículos de la constitución política antes mencionados, así como en el artículo 32 de la Ley 70 de 1993 (Congreso de Colombia, 31 de agosto de 1993). De hecho, este artículo precisa:

El Estado colombiano reconoce y garantiza a las comunidades negras el derecho a un proceso educativo acorde con sus necesidades y aspiraciones etnoculturales. La autoridad competente adoptará las medidas necesarias para que en cada uno de los entornos educativos los currículos se adapten a esta disposición.

Pese a la intención de la ley de favorecer las minorías étnicas, en particular a los grupos negros, afrocolombianos, raizales y palenqueros, la realidad cotidiana demuestra que existe gran resistencia de parte de las secretarías de educación hacia la inclusión de asuntos afrocolombianos en el currículo. Además, debe resaltarse que el artículo 39 de la misma Ley 70 de 1993 (Congreso de Colombia, 31 de agosto de 1993) establece lo siguiente:

El Estado velará para que en el sistema nacional educativo se conozca y difunda el conocimiento de las prácticas culturales propias de las comunidades negras y sus aportes a la historia y a la cultura colombiana, a fin de que ofrezcan una información equitativa y formativa de las sociedades y culturas de estas comunidades. En las áreas de sociales de los diferentes niveles educativos se incluirá la cátedra de estudios afrocolombianos conforme con los currículos correspondientes.

De acuerdo con el artículo 14 de la Ley General de Educación de 1994 (Congreso de Colombia, 8 de febrero de 1994), es obligatorio el fomento de la diversidad cultural en los niveles de educación preescolar, básica y media. Por consiguiente, se hace necesario que el Gobierno nacional de Colombia adopte medidas tendientes al cumplimento con lo dispuesto en dicha ley, en la Ley 70 de 1993 (Congreso de Colombia, 31 de agosto de 1993) y en la Constitución política de 1991, entre otras normas.

Asimismo, en el ámbito internacional vale la pena resaltar lo expresado en el artículo 14 de la Convención Internacional sobre la Eliminación de Todas las Formas de Discriminación Racial (ONU, 1969). Además, es pertinente destacar la relevancia que tiene para el currículo el desarrollo de la Cátedra de Estudios Afrocolombianos, en correspondencia con el Convenio 169 de la OIT (2014), el cual forma parte del bloque de constitucionalidad. Lo anterior involucra el sentido de conservación de la identidad cultural 


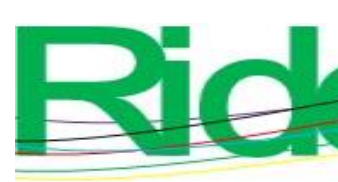

Revista Iberoamericana para la
Investigación y el Desarrollo Educativo
ISSN $2007-7467$

a través de la educación impartida, no solo a los miembros de estas minorías étnicas, sino a toda la población colombiana. En ese sentido, el artículo 22 de dicho convenio de la OIT (2014) expresa:

1) Deberán tomarse medidas para promover la participación voluntaria de miembros de los pueblos interesados en programas de formación profesional de aplicación general.

2) Cuando los programas de formación profesional de aplicación general existentes no respondan a las necesidades especiales de los pueblos interesados, los Gobiernos deberán asegurar, con la participación de dichos pueblos, que se pongan a su disposición programas y medios especiales de formación.

3) Estos programas especiales de formación deberán basarse en el entorno económico, las condiciones sociales y culturales, y las necesidades concretas de los pueblos interesados. Todo estudio a este respecto deberá realizarse en cooperación con esos pueblos, los cuales deberán ser consultados sobre la organización y el funcionamiento de tales programas. Cuando sea posible, esos pueblos deberán asumir progresivamente la responsabilidad de la organización y el funcionamiento de tales programas especiales de formación, si así lo deciden.

Por su parte, el artículo 23 expresa:

1) La artesanía, las industrias rurales y comunitarias, y las actividades tradicionales relacionadas con la economía de subsistencia de los pueblos interesados como la caza, la pesca, la caza con trampas y la recolección deberán reconocerse como factores importantes del mantenimiento de su cultura, y de su autosuficiencia y desarrollo económicos. Con la participación de esos pueblos, y siempre que haya lugar, los Gobiernos deberán velar porque se fortalezcan y fomenten dichas actividades.

2) A petición de los pueblos interesados, deberá facilitárseles, cuando sea posible, una asistencia técnica y financiera apropiada que tenga en cuenta las técnicas tradicionales y las características culturales de esos pueblos, y la importancia de un desarrollo sostenido y equitativo (OIT, 2014).

Finalmente, el artículo 26 señala que “deberán adoptarse medidas para garantizar a los miembros de los pueblos interesados la posibilidad de adquirir una educación a todos los niveles, por lo menos en pie de igualdad con el resto de la comunidad nacional" (OIT, 2014).

Ahora bien, cuando se habla de la Cátedra de Estudios Afrocolombianos se alude a un escenario para contribuir a propiciar una educación intercultural e inclusiva que promueva 


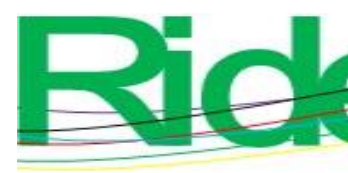

Revista Iberoamericana para la
Investigación y el Desarrollo Educativo
ISSN $2007-7467$

el respeto de los derechos humanos para todos. Esto dista de lo que por error asume un número importante de profesores, para quienes la finalidad principal de esta es ofrecer una educación para la población negra. Lejos de aportar a la construcción de una cultura en valores, esta visión reduccionista que se tiene sobre la cátedra profundiza aún más la discriminación racial, incidiendo negativamente en su implementación en la mayoría de las instituciones educativas del país. Así, pese a los más de 20 años de creada la Cátedra de Estudios Afrocolombianos, aún persiste cierta resistencia por parte del profesorado para su implementación en el currículo, y falta una decisión política por parte del Ministerio de Educación Nacional y las secretarías de educación.

Por otra parte, el capítulo III de la Ley General de Educación de 1994 (Congreso de Colombia, 8 de febrero de 1994), en su artículo 55, señala que la educación para grupos étnicos es aquella que "se ofrece a los grupos o a las comunidades que integran la nacionalidad y que poseen una cultura, una lengua, una tradición y unos fueron propios y autóctonos".

En ese orden de ideas, tanto las normas nacionales como los acuerdos internacionales suscritos por Colombia respaldan la relevancia de la Cátedra de Estudios Afrocolombianos en favor de los derechos humanos de los grupos étnicos. De ahí la razón de ser de su obligatoriedad en todos los niveles de escolaridad tanto en la básica como en la educación media de la escuela colombiana. Por tanto, esta se debe ofrecer a todos los estudiantes y no solo a las comunidades negra, afrocolombiana, raizal y palenquera.

Ahora bien, un aporte clave en favor de la defensa de la diversidad cultural es el generado por la Convención de Patrimonio Mundial, Cultural y Natural, aprobada por la Organización de las Naciones Unidas para la Educación, la Ciencia y la Cultura [Unesco] (1972). Este tratado internacional firmado por la República de Colombia propone promover la identificación, la protección y preservación del patrimonio cultural y natural de todo el mundo, el cual es considerado valioso para la humanidad.

Asimismo, en su reunión núm. 31, el 2 de noviembre de 2001, en la ciudad de París, la Unesco (2001) emitió la Declaración Universal sobre la Diversidad Cultural. Se trata de un instrumento jurídico que eleva la diversidad cultural a la categoría de patrimonio común de la humanidad. La ONU (2001), por su parte, expidió la Resolución 57/249 el 21 de mayo de 2001, proclamado desde entonces Día Mundial de la Diversidad Cultural para el Diálogo y el Desarrollo. Y en coherencia con esta resolución, el Gobierno nacional de 


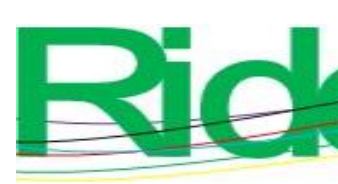

Revista Iberoamericana para la
Investigación y el Desarrollo Educativo
ISSN $2007-7467$

Colombia expidió la Ley 725 de 2001 (Congreso de Colombia, 30 de diciembre de 2001), por la cual se establece el 21 de mayo como el Día Nacional de la Afrocolombianidad.

Para la Unesco (2001), es claro que la cultura engloba las artes y las letras, modos de vida, sistemas de valores, tradiciones y creencias. Por tanto, para este organismo, la protección y promoción de la diversidad cultural es una prioridad que plantea el desafío de defender la capacidad creativa a través de sus múltiples formas materiales e inmateriales, así como garantizar la convivencia pacífica. De acuerdo con este mismo organismo, un plan de acción para la aplicación de la Declaración Universal sobre Diversidad Cultural debe efectuar lo siguiente:

a) Propiciar, a través de la educación, una toma de conciencia de la importancia de la diversidad cultural; para ello es necesario mejorar la formación docente y los programas escolares.

b) Incorporar al proceso educativo métodos pedagógicos tradicionales, con el fin de preservar y optimizar los métodos culturalmente adecuados para la comunicación y apropiación del saber.

c) Respetar y proteger los sistemas de conocimientos tradicionales.

d) Elaborar políticas y estrategias de preservación y valorización del patrimonio cultural y natural (Unesco, 2001, p. 4).

Continuando con este análisis, es indispensable valorar algunas sentencias emanadas por la Corte Constitucional de Colombia, entre estas la Sentencia T-496/96 (Corte Constitucional, 26 de septiembre de 1996) sobre diversidad cultural. En ella se afirma que Colombia es un Estado multiétnico y pluricultural, donde los principios de la diversidad y de la integridad personal no son simplemente una declaración retórica. Por el contrario, estos se constituyen en principios fundamentales de la diversidad étnica y cultural, la cual proyecta, en el plano jurídico, el carácter democrático y participativo de la república y obedece a la aceptación de la alteridad, ligada a la multiplicidad de formas de vida y sistemas de comprensión de mundo diferentes a los de la cultura occidental.

La anterior declaración de la Corte Constitucional de Colombia refleja la importancia que implica abordar desde la escuela el problema de la diversidad cultural, el derecho al pensamiento divergente, a expresar libremente sus planteamientos y sus expresiones culturales. Por tanto, la Cátedra de Estudios Afrocolombianos es una oportunidad, un espacio vital para la reflexión sobre la cultura y es indispensable para propiciar una educación inclusiva e intercultural en la escuela colombiana. De ahí que sea 


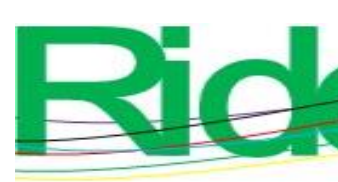

Revista Iberoamericana para la
Investigación y el Desarrollo Educativo
ISSN $2007-7467$

fundamental contar con profesionales cualificados que preparen a los estudiantes en una cultura por el respeto a la diversidad étnica y cultural, además de las competencias genéricas y específicas, como tradicionalmente lo hace la escuela.

De acuerdo con Carbonell (2002), los problemas interculturales trascienden el espacio de la escuela y son un conflicto político de gran trascendencia. Hace falta voluntad, actitud y unas actuaciones políticas decididas a trabajar contra la exclusión social. Ello demanda inversión económica orientada a mejorar la calidad de vida de los estudiantes y la población en general. Adicional a lo anterior, Santos (2002) sostiene que la educación intercultural debe revisar los valores morales al interior del centro educativo e indica que tiene la responsabilidad de visibilizar las diversas culturas, aportando herramientas que permitan entender la diversidad cultural como un fenómeno social.

Por encargo social, a la escuela le corresponde educar a sus estudiantes en la apropiación de conocimientos, en el desarrollo de habilidades y competencias, así como en la formación de actitudes y valores morales. Sin embargo, en lo que atañe a los valores morales, la escuela siempre se ha identificado con las normas y costumbres de la mayoría de la población (en este caso, de la población mestiza) que ha gobernado el país desde tiempos inmemoriales, con normas que muchas veces ignoran los derechos de las minorías étnicas.

Como se ha expuesto a lo largo de este artículo, aún persiste resistencia en la gran mayoría de las instituciones educativas (tanto públicas como privadas) para la implementación de la Cátedra de Estudios Afrocolombianos a lo largo y ancho del país. En coherencia con lo anterior, se aplicó una encuesta a un grupo de líderes de las poblaciones negra, afrocolombiana, raizal y palenquera para conocer la percepción que estas comunidades étnicas tienen sobre los problemas por los que atraviesa la ejecución de esta cátedra.

Se debe seguir explorando sobre la implementación de la Cátedra de Estudios Afrocolombianos en las Facultades de Educación, las Escuelas Normales, así como en las instituciones educativas de básica y media, de manera que se busquen espacios académicos o alternativas educativas dentro de la cultura escolar, de manera que contribuyan propiciar el respecto por los derechos humanos de las minorías étnicas dentro y fuera de las instituciones educativas. 


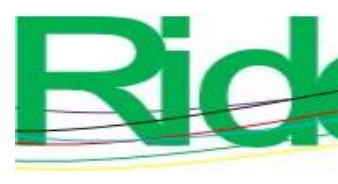

Revista Iberoamericana para la Investigación y el Desarrollo Educativo ISSN $2007-7467$

\section{Conclusiones}

Lo mencionado en líneas anteriores permitió articular el problema de investigación, los objetivos, la metodología y las demás partes de este trabajo, lo cual permite arribar a las siguientes conclusiones.

Después de más de 20 años de creada la Cátedra de Estudios Afrocolombianos, esta aún sigue sin implementarse en los currículos de la mayoría de las escuelas colombianas, a pesar de su carácter obligatorio, según lo previsto por la legislación colombiana expresada en el artículo 1 del Decreto 1122 de 1988 (Presidencia de la República de Colombia, 23 de junio de 1998). Por tal razón, un grupo importante de líderes negros, afrocolombianos, raizales y palenqueros de Colombia considera que ha faltado voluntad política por parte del Ministerio Nacional de Educación y de las secretarías de educación para el desarrollo y la puesta en marcha de políticas públicas. Esto significa que se debe propiciar el cumplimiento de la ley, con la intención de que la implementación de la cátedra sea una realidad para estos grupos étnicos y no se asuma como una simple norma descontextualizada.

El estudio realizado arrojó que la mayoría de líderes de las comunidades negra, afrocolombiana, raizal y palenquera considera que la implementación de la Cátedra de Estudios Afrocolombianos en el currículo de la escuela colombiana es fundamental para propiciar el respeto por los derechos humanos, la diversidad cultural y la inclusión de grupos étnicos.

El análisis documental y la encuesta develaron que aún persisten el racismo y la discriminación en la escuela colombiana por cuestiones étnicas, situación que afecta la autoestima de los estudiantes de las comunidades negra, afrocolombiana, raizal y palenquera, ocasionando inseguridad y bajo desempeño académico. Esta situación es contraria a lo previsto en la Constitución política de Colombia, la Ley General de Educación de 1994 (Congreso de Colombia, 8 de febrero de 1994), la Ley 70 de 1993 (Congreso de Colombia, 31 de agosto de 1993) y el acuerdo de la OIT de 1989 (2014). Por consiguiente, se requiere la implementación de la Cátedra de Estudios Afrocolombianos con el propósito de promover la diversidad cultural entre los ciudadanos y el respeto de los derechos humanos.

Como conclusión final de este estudio, debe precisarse que la falta de políticas públicas efectivas por parte del Ministerio de Educación Nacional, la ausencia de organización de las comunidades negra, afrocolombiana, raizal y palenquera, así como el desconocimiento de los contextos (histórico, político, escolar...) por parte de las secretarías 


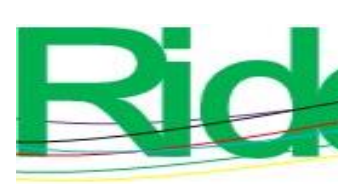

Revista Iberoamericana para la
Investigación y el Desarrollo Educativo
ISSN $2007-7467$

de educación constituyen los principales problemas para la implementación de Cátedra de Estudios Afrocolombianos en los currículos de las escuelas de la República de Colombia.

\section{Futuras líneas de investigación}

A manera de recomendaciones este estudio propone realizar investigaciones que emprendan la búsqueda de alternativas que contribuyan a propiciar el respeto por los derechos humanos para los grupos étnicos correspondientes a la población negra, afrocolombiana, raizal y palenquera en las instituciones educativas de educación básica y media donde no se ha implementado la Cátedra de Estudios Afrocolombianos.

Por otra parte, se plantea la necesidad de realizar investigaciones conjuntas entre el Ministerio de Educación, las secretarías de educación, las universidades e instituciones educativas de nivel básico y medio, de manera que contribuyan a la búsqueda de alternativas que promuevan la implementación de la Cátedra de Estudios Afrocolombianos en la mayoría de los colegios del país.

\section{Referencias}

Carbonell, F. (2002). Educación intercultural: principales retos y requisitos indispensables. Kikiriri, (65) 63-68.

Cerda, G. (1994). La investigación total. Bogotá, Colombia: Editorial Magisterio.

Congreso de Colombia. (31 de agosto de 1993). Ley 70 de 1993. Por la cual se desarrolla el artículo transitorio 55 de la Constitución Política. Diario Oficial, (41.013). Recuperado de https://www.acnur.org/fileadmin/Documentos/BDL/2006/4404.pdf

Congreso de Colombia. (8 de febrero de 1994). Ley 115 de 1994. Por la cual se expide la Ley General de Educación. Diario Oficial, (41.214). Recuperado de https://www.mineducacion.gov.co/1621/articles-85906_archivo_pdf.pdf.

Congreso de Colombia. (30 de diciembre de 2001). Ley 725 de 2001. Por la cual se establece el Día nacional de la afrocolombianidad. Diario Oficial, (44.662). Recuperado de http://www.mincultura.gov.co/areas/poblaciones/noticias/Paginas/D\%C3\%ADaNacional-de-la-Afrocolombianidad.aspx.

Constitución Política de Colombia. (1991).

Corte Constitucional. (26 de septiembre de 1996). Sentencia T-496/96. Gaceta de la Corte Constitucional. 


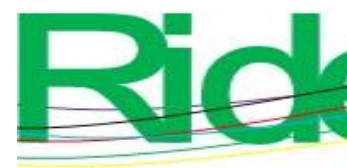

Revista Iberoamericana para la
Investigación y el Desarrollo Educativo
ISSN $2007-7467$

Freire, P. (1990). La naturaleza política de la educación. Cultura, poder y liberación. Barcelona, España: Paidós.

Freire, P. (2001). Pedagogía de la indignación. España: Morata.

Fricker, M. (2007). Epistemic Injustice. Power and the Ethics of Knowing. Oxford, United Kingdom: Oxford University Press.

Garcés, D. (2009). Desafios y tensiones sobre la formación de etnoeducadores afrocolombianos. Universidad del Pacífico.

Hernández, R., Fernández, C. y Baptista, P. (2014). Metodología de la Investigación (6. ed.). Ciudad de México, México: McGraw-Hill.

López, M. (2001). Cortando las amarras de la escuela homogeneizante y segregadora. Revista de Educación, 21(3), 15-53.

Ministerio del Interior [Miniterior]. (2019). “Diagnóstico: implementación de la Cátedra de Estudios Afrocolombianos, experiencias y perspectivas en el respecto de la diversidad étnica, y cultural de la nación”. Recuperado de http://www.mininterior.gov.co/

Organización de las Naciones Unidas [ONU]. (1969). Convención Internacional sobre la Eliminación de Todas las Formas de Discriminación Racial. Recuperado de https://www.ohchr.org/Documents/ProfessionalInterest/cerd_SP.pdf.

Organización de las Naciones Unidas [ONU]. (2001a). Convención sobre la Protección del Patrimonio Cultural Subacuático. Recuperado de http://portal.unesco.org/es/ev.phpURL_ID=13520\&URL_DO=DO_TOPIC\&URL_SECTION=201.html.

Organización de las Naciones Unidas [ONU]. (2001b). Resolución aprobada por la Asamblea General 57/249. Cultura y desarrollo. Recuperado de https://undocs.org/es/A/RES/57/249.

Organización de las Naciones Unidas para la Educación, la Ciencia y la Cultura [Unesco]. (1972). Convención sobre la Protección del Patrimonio Mundial, Cultural y Natural. Recuperado de https://culturalrights.net/descargas/drets_culturals392.pdf.

Organización de las Naciones Unidas para la Educación, la Ciencia y la Cultura [Unesco]. (2001). Declaración Universal de la Unesco sobre la Diversidad Cultural. Recuperado de

http://portal.unesco.org/es/ev.php-

URL_ID=13179\&URL_DO=DO_TOPIC\&URL_SECTION=201.html.

Organización Internacional del Trabajo [OIT]. (2014). Convenio núm. 169 de la OIT sobre pueblos indígenas y tribales. Lima, Perú: Organización Internacional del Trabajo. 


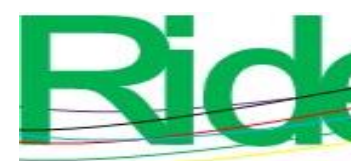

Recuperado de https://www.ilo.org/wcmsp5/groups/public/---americas/---rolima/documents/publication/wcms_345065.pdf.

Pereira, Z. (2011). Los diseños de método mixto en la investigación en educación: una experiencia concreta. Revista Electrónica Educare, 15(1), 15-29.

Presidencia de la República de Colombia. (18 de mayo de 1995). Decreto 804 de 1995 por medio del cual se reglamenta la atención educativa para grupos étnicos. Diario Oficial, (41853). Recuperado de http://www.suinjuriscol.gov.co/viewDocument.asp?ruta=Decretos/1169166.

Presidencia de la República de Colombia. (26 de diciembre de 1995). Decreto 2249 de 1995. Por el cual se conforma la Comisión Pedagógica de Comunidades Negras de que trata el artículo 42 de la Ley 70 de 1993. Diario Oficial, (42163). Recuperado de https://www.urosario.edu.co/jurisprudencia/catedra-vivaintercultural/Documentos/Decreto_2249_de_1995.pdf.

Presidencia de la República de Colombia. (13 de septiembre de 1996). Decreto 1627 de 1996 por el cual se reglamenta el artículo 40 de la Ley 70 de 1993. Diario Oficial, (42877). Recuperado de http://www.suin-juriscol.gov.co/viewDocument.asp?id=1321802.

Presidencia de la República de Colombia. (23 de junio de 1998). Decreto 1122 de 1998 por el cual se expiden normas para el desarrollo de la Cátedra de Estudios Afrocolombianos en todos los establecimientos de educación formal del país y se dictan otras disposiciones. Diario Oficial, (43325). Recuperado de http://www.suinjuriscol.gov.co/viewDocument.asp?ruta=Decretos/1861091.

Rodríguez, G., Gil, J. y García, E. (1996). Metodología de la investigación cualitativa. Málaga, España: Aljibe.

Ruiz, C. (1998). Instrumentos de investigación educativa. Barquisimeto, Venezuela: Cideg. Santos, M. (2002). Teoría y práctica de la educación intercultural. Santiago de Compostela, España: PPU.

Skliar, C. (2002). Alteridades y pedagogía: o... ¿y si el otro no estuviera ahí? Educação \& Sociedade, (79), 85-123. Recuperado de http://www.scielo.br/pdf/es/v23n79/10851.pdf.

Somin, I. (2010). Deliberative Democracy and Political Ignorance. Critical Review, 22(2-3), 257-262.

Stake, R. E. (1998). Investigación con estudio de casos. Madrid, España: Ediciones Morata. 